\title{
Touching Distance: The underlying Russophilia in the Skripal Case Coverage in Greek Press
}

\author{
Panagiotis Paschalidis ${ }^{1,3}$, George Siakas ${ }^{2,3}$ \\ ${ }^{1}$ Department of Communication and Digital Media, University of Western Macedonia, Greece \\ ${ }^{2}$ Democritus University of Thrace: Komotini, Greece \\ ${ }^{3}$ Public Opinion Research Unit at the University of Macedonia Research Institute, Greece \\ Correspondence: Panagiotis Paschalidis, Department of Communication and Digital Media, University of Western \\ Macedonia, Greece.
}

Received: December 16, 2021

Accepted: January 25, 2022

Online Published: January 27, 2022

doi:10.11114/smc.v10i1.5426

URL: https://doi.org/10.11114/smc.v10i1.5426

\begin{abstract}
Theories of mediatization and domestication provide an analytical framework in understanding how patterns of interpretation are related to the public opinion's attitudes towards actors and topics. In this study, we focus on the coverage of the Skripal case by major Greek newspapers in March 2018 in a pursuit to determine the variety of dispositions towards Russia. The Greek media's coverage seems to comply with a disengaged approach: more news than views. The majority of news reports -instead of opinions- can be regarded as an effect of awkwardness or a choice not to provide analysis on Russia, even though the abundant news reports have the exact opposite effect of maintaining the public's vivid interest. By performing a content analysis on articles with references to Russia, we seek to look beneath this veneer. We suggest that the Greek newspapers' coverage is linked with more structural traits, such as Russophilia, as we identify several distinct subcultures in the press when it comes to dispositions towards Russia.
\end{abstract}

Keywords: Skripal case, Russophilia, Greek media, mediatization, domestication

\section{Introduction}

Contemporary Russophilia remains an underrated research topic, especially in Southeastern Europe. While in the European mainland the support rates for Russia resemble those in North America, presenting a steady fall in the last decade (Huang, 2020), the case in the Southern part of Europe is a bit different. For instance, Greece, along with Bulgaria and Slovenia exceed the median support for Russia of their EU counterparts (Huang \& Cha, 2020), presenting an astonished positive outlook. Even though there is some noticeable decrease in the last years (DiaNEOsis, 2016-2020), this phenomenon is still on the agenda.

Some recent studies attempted to explore the phenomenon by shedding some light on its various aspects. Contemporary Greek Russophilia could be correlated with far-right sentiments (Petsinis, 2014), or is seen as a characteristic of the Greek political culture and the underdog sentiment (Ntampoudi, 2014a, 2014b; Siakas \& Paschalidis, 2021). Interestingly, these recent projects have revealed some valuable insights. On the one hand, macroscopic approaches attempt to identify factors that could become game changers or affect the stability in the area (Armakolas \& Triantafyllou, 2017). On the other hand, the revelation of micro-approaches, such as the component of "hard" or "soft" Russophilia could be useful in understanding behaviors and potential future attitudes (Siakas \& Paschalidis, 2021). Although these attempts provide an adequately informative context, there is a complementary question still untouched. What's happening on the supply side? What is the actual depiction of Russophilia in the media?

The supply side is far from just a plain field of forces in which each actor performs on its own. The political establishment, the elites, the media, interest groups, all together entangle into an antagonism of influencing politics and the balance of power (Mouffe, 2002; Rasmussen, 2016). This makes the understanding of the driving forces a hard endeavor. This paper attempts to delve deeper in this struggle, by exploring one of the major forces that operate in this field: the mass media. There is a special focus on the most traditional medium, the print press. Additionally, a content analysis case study seeks to identify patterns of approaching a hot issue from different perspectives. The case study under exploration is the so-called "Skripal case", one of the most prominent and wide expulsion of Russian diplomats in the EU during the last decade. 
The Skripal case received a lot of attention around the world. A key interpretative pattern was the Russian assassination plots against former defectors (i.e. the poisoning of Litvinenko in 2016) (Hanni \& Grossman, 2020). The case incited numerous op-eds and commentaries, particularly in Western countries, on the role of Russia in international affairs. Many media around the world focused their analysis on the implications of the case for the consolidation of a "Cold-War" climate between Russia and the West (Boyd-Barrett \& Mirrlees, 2020).

On 4 March 2018, Sergei Skripal, a former Russian military intelligence officer and his daughter Yulia, were poisoned near their home in Salisbury, UK. Within a few days, the UK government accused Russia of being responsible for a chemical attack with the neurotoxic agent "Novichok". According to the UK government, Russia attempted to kill Sergei Skripal in the context of punitive action, since he had been a double agent working for the UK in the early 2000's. Russia denied all allegations and any responsibility in the event (Deutsche Welle, 2018; Financial Times, 2018). On 14 March 2018, the UK government announced the expulsion of 23 Russian diplomats.

On 17 March, Russia retaliated with the expulsion of the same number of British diplomats. In the following days, many EU countries as well as countries around the world expelled Russian diplomats in a gesture of solidarity to the UK. On 26 March 2018 the US government announced the expulsion of 60 Russian diplomats. On 30 March 2018, Russia announced the expulsion of the same number of US diplomats. In the following months, the media focused on the investigations in the UK or Russia's reactions. Progressively, however, the media coverage fainted. In early 2019, the UK government insisted that Russia was behind the attack, whilst Russia continued to deny it.

Greece, along with Austria, Portugal and Cyprus, did not expel Russian diplomats or recall its Ambassador from Moscow. Nonetheless, all countries expressed their solidarity to the UK on the occasion of the EU Council dedicated, almost exclusively, to the Skripal case on 22 March 2018 (The New York Times, 2018). A close look at the coverage of Greek newspapers of that event will yield very few results. In effect, the most elaborate article on the issue comes from a news report by Bloomberg ("May Served Secrets Over Dinner to Win EU Allies for Russia Fight", 23 March 2018), republished by Kathimerini in Greece.

A striking element differentiating the approach of the Greek media in the wider context of Western media, is the overwhelming domination of news reports and the very limited number of opinions. By choosing to analyze as little as possible the Skripal case and the Greek position, Greek newspapers conveyed a rather contradictory message to their public. The continuous coverage can be understood as a constant reminder and an invitation to show a special interest in the case and yet, the absence of analysis epitomizes the evasiveness to frame the case, to incorporate it into specific interpretative frameworks.

The online version of the newspapers included a daily interest with numerous news reports. Most commonly, these articles merely reproduced the information provided by the major news agencies, the "Big Three": AP, Reuters and AFP. Fewer articles presented information by the Athens-Macedonian News Agency (ANA-MPA). However, the absence of opinions in the Greek newspapers is rather perplexing. The dependence on news agencies as a means to cover foreign news is a typical phenomenon. The general framework of the "globalization of news" (Galtung \& Vincent, 1992; Boyd-Barrett, 1997; Boyd-Barrett \& Rantanen, 1998) explains the mechanics of this reliance. Other studies explore the "homogenization" of foreign news within the context of globalization (Baden \& Tenenboim-Weinblatt, 2017; Beckers et al., 2019).

News reports tend to be more neutral and less biased while opinions aim at defending or rejecting specific arguments (Kruger et al., 2017). In terms of journalistic genres, news reports and opinions are clearly distinguishable: Reports are texts that inform via the juxtaposition of facts whilst opinions or op-eds are texts that combine information with interpretation and resolution (Sterling, 2009). Additionally, opinions are commonly authored by journalists of a newspaper whereas an op-ed is authored by a personality external to the newspaper. In newspapers, reports and opinions encapsulate two baseline and distinct functions: the informative, which is served by other types such as interviews, and the persuasive, exemplified by the editorials, the commentaries, the reviews and the columns (Charaudeau \& Maingueneau, 2002). Indeed, a smaller amount of news reports and very few opinions could possibly indicate a more homogenized or even disengaged standpoint. However, this was not the case with the Greek newspapers. Nevertheless, they paid close attention to the case by publishing several news reports.

\section{Material studied and Hypotheses}

Our main interest is to look deeper into the ways the Skripal case was presented by Greek media. This is driven, firstly, by the international impact of the case that should have mobilized Greek media, and secondly, by the specific importance to Greece, given the varying Russophile attitudes in Greek public opinion. Our research question is formulated in the following manner:

RQ: What was the overall coverage, as for example the quality and the density of the Skripal case in Greek media? 
The Skripal case is viewed as a case study that facilitates the measurement of Russophile dispositions in the Greek media. In particular, the main case study lies on the exploration of the paper media, and especially the Greek newspapers. Our first hypothesis lies on the assumption that a low intensity coverage would have been manifested by a generalized lack of interest (few news and no views). However, the coverage of the Greek newspapers indicates engagement and intensity (much news while at the same time there are few views). Therefore, it must be interpreted in a more composite way and correlated with the attitudes towards Russia and Russophilia. This emerges from our second hypothesis.

H1: The coverage of the Greek newspapers can be summed up by the notion of awkwardness or discomfort towards the Skripal case.

The second hypothesis draws from the "domestication theory" and the deduction that the media not only interpret foreign news according to the specific country culture, but also according to various subcultures that exist within it. In the Skripal case, the approach of "domestication of foreign news" (Gurevitch et al., 1991; Alassutari et al., 2013) is expected to have an effect. This stresses the pivotal role that media play in presenting and explaining foreign news via patterns and choices that correspond to the culture or even the dominant ideologies pertaining to their domestic audiences (Gurevitch et al., 1991; Clausen, 2004). Added to this standpoint, the process of domestication could be close to the configuration of social and cultural elements through media forms, as supported by the "mediatization" framework (Hjarvard, 2008).

H2: There will be differentiations in the image of Russia related to the differences of subcultures that newspapers express or are related to.

This study does not claim that taking the Skripal case as a case study and the Greek newspapers' coverage for one month can explain the phenomenon of Russophilia to a full extent. There are two limitations, which do not hamper, in our view, its pertinence: firstly the data and secondly the period. Regarding the data, we scrutinize an event that took place more than three years ago. Under that instance, our aim is to provide one of the first, albeit informed and theorized, approaches on the way contemporary Russia is represented by the Greek media. The particularity of the Skripal case was that contrary to other topics in the international news agenda, there was a constant focus on Russian policy. Thematically speaking, it has been a case with a more or less undifferentiated storyline without major regional or global dimensions.

In regards to the limitation of the coverage period, this is explained by the fact that the interest of the coverage was fading at a relatively fast pace. Our choice to focus our study in March enabled the inclusion of most, if not all, of the case's facets; the incidents in the UK, the diplomatic tension and the reactions of the USA and EU countries.

The following section presents the theoretical framework that bridges the way the media cover an issue within the paradigm of domestication. Subsequently, we will unfold the methodology of the case study and address both hypotheses and in the conclusions, we will provide a ground for further elaboration.

\section{Elements of the theory and field descriptions}

The depiction of Russia in the Greek media is an under-researched topic. In recent years there have been significant contributions particularly in the realm of political science covering mainly the supply side of the political environment.

Favorable views towards Russia have been on the rise during Greece's economic adversities in the 2010's (Petsinis, 2016; Ntampoudi, 2014a, 2014b). It has been also suggested that such dispositions- notably at the level of political actors- related to a populist rationale (Petsinis, 2014; Efthymiopoulos, 2016; Tsebelis, 2016; Zahariadis, 2017); the idea, for instance, that Russia could be a political and economic alternative model for Greece is not only illustrative of the frustration linked with the economy. It is also highly indicative of the dismay of some political actors with Western institutions and countries identified with the harsh policies imposed on Greece during the bailout programmes. In the public opinion level, Russophilia is considered as a part of the "underdog culture" (Diamantouros, 2000; Marantzidis \& Siakas, 2019). Further, the hypothesis of the existence of two groups, one with sets of beliefs corresponding to pro-Western and pro-reformist ideas, another with a pro-Russian stance, conservative and ethnocentric values could be confirmed. Thus, Russophile dispositions are not homogenous, as there is a soft (one third of the population) and a hard-core variant that corresponds to one fourth of the population.

Our approach differs from the above attempts as it focuses on the relation between the media's presentation of foreign news and the formatting process on how representations become attitudes towards a particular aspect of this coverage. Nevertheless, the media's input is hardly the only determinant factor when it comes to the general public's dispositions. The public sphere consists of several components such as the government, the elites, the media, groups of interest, the public opinion et al. But it is the interplay and often the antagonism among these actors that can shift attitudes towards a particular direction. Entman's "cascade mode" (2003) suggests an eventual sequence among the basic components 
(government, elites, media, and public opinion) and emphasizes a process of interaction and dependency. Baum and Potter (2008) proposed the concept of the "marketplace" in order to describe the dynamics between the various actors. This approach doesn't define the part that could be more impactful, as what matters is the actual equilibrium rather than the driving forces that move towards the balance point. On an application of the above, a recent case study, (Armakolas \& Siakas, 2021) explored influences in shaping the Greek public opinion towards the naming dispute between Greece and North Macedonia.

Our study is based on the supply side and the mediatization framework. This transposes the analytical interest from the generic presentation of foreign news to the more specific presentation of foreign news according to the particular culture or sub-cultures of a society. Mediation highlights the media's capacity to shape the perception of reality, along with interpersonal communication and personal experience (Shehata \& Stromback, 2014). In effect, Marshall McLuhan's "the medium is the message" formula (1964) has been completed with the axiome that mediated reality is more important than objective reality (Stromback, 2008). Many works have emphasized how dependent politics have become on the media's channeling of information between political actors and the public, thus forging the sentiment of a political community or system (Anderson, 1983; Bennett \& Entman, 2001; Mazzoleni \& Schulz, 1999).

Hjarvard's systematic approach on mediatization (2008) emphasizes the growing dependence of contemporary societies on the media's daily input in various fields. In effect, he refers to the "institutionalization" of the media themselves as "the process whereby society to an increasing degree is submitted to, or becomes dependent on, the media and their logic." (Hjarvard, 2008: p. 113). Through mediatization, the media have become integrated into different society levels (i.e. politics, culture, economy) (Hjarvard, 2013; van der Meer et al., 2019). In the coverage of international news, the mediatization approach implies that the media apply a set of criteria that surpass that of newsworthiness. Galtung and Ruge's work (1965) explains that a powerful country, like Russia, will receive constant media coverage by default. However, this structural trait does not tell the whole story; it doesn't interpret the long-standing patterns and habits of depicting and mediatizing Russia. This is why the media's commercial logic, the newsworthiness criteria and even political orientation cannot be taken as the only factors shaping editorial choices.

The theory of domestication is another valuable framework with reference to the mediatization of foreign news. Its rationale is that within this globalized framework, national media are not passive recipients but rather active participants in presenting foreign news to their audience. According to Clausen (2004), domestication refers to the process of the appropriation of foreign news according to the specific cultural traits and national context. For Gurevitch et al. (1991), the media hold both global and culturally specific orientations that help them to render foreign events more appealing and relevant to domestic audiences.

However, there isn't a single approach of domestication. Clausen refers to "strategies of domestication" (2004) as layers depending on which aspect of news coverage is in focus. The emphasis could be either on external and aesthetic aspects (i.e. language, style or use of visual elements) or on political and cultural aspects (i.e. ideological considerations, national interests or cultural traits). In the case of political aspects, Liebes (1992) has emphasized the difference in the presentation of foreign news along the lines of an "ours" and "theirs" issue. The hypothesis in this context is that if an issue relates directly to national foreign policy, the media's approach will be more biased and ethnocentric. Outside this framework, media coverage would be more distant, neutral, and "professional".

Nonetheless, this boundary may not always be so clear. Handley and Ismail (2010) suggest that such views can be "naturalized" and incorporated into the media's presentation in two variations: (i) a more professional and distant and (ii) a more biased one. In other words, it seems that a specific cultural context with all its particular traits or subcultures, could function as a rather opaque and yet influential framework.

Another strategy of domestication which bridges external and internal traits of the media's coverage of foreign news is the "news vs. views" balance. According to Clausen (2004) a coverage which is more focused on the news, such as factual aspects, indicates a more traditional and disengaged approach. In contrast, an approach with more views could indicate a more partisan and commercial logic. This for example will instigate debate and public discussions or support a specific interpretation.

Thus, domestication can overlap with mediatization. However, they may highlight divergent processes.. When covering the Skripal case, the Greek media do not discover Russia or the UK, for that matter, for the first time. They have a long and institutionalized experience in covering foreign news with a particular logic. They also have a rather particular mode(s) for domesticating information on Russia. It is therefore our key interest to decode their coverage. Russophilia, in the context of our study, is precisely the cultural framework and factor that could have oriented the Greek newspapers' approach. 


\section{Methods}

The period of study was the month of March 2018. The first step in our methodological approach was the selection of the newspapers' sample. Newspapers with distinctive political orientation. were studied (Boukala \& Dimitrakopoulou, 2017; Nikisianis et al., 2018, Papadogiannis, 2019). In particular, the coverage of the Skripal case was studied in 1.

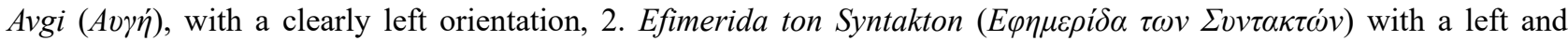

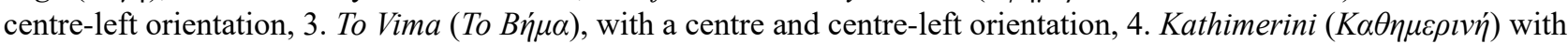

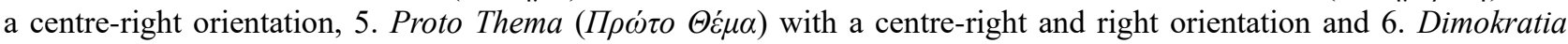

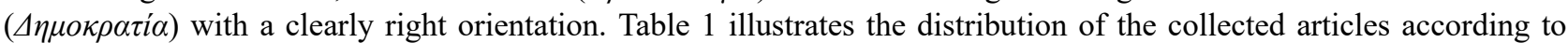
their source. These articles correspond to the total number of articles published by each of the newspapers of the sample in relation to the Skripal case.

Table 1. The total number of articles collected from the newspapers of our sample

\begin{tabular}{ll}
\hline Newspapers & Number of articles \\
\hline Avgi & $\mathbf{5 6}$ \\
Efimerida ton Syntakton & $\mathbf{3 1}$ \\
To Vima & $\mathbf{7 1}$ \\
Kathimerini & $\mathbf{8 2}$ \\
Proto Thema & $\mathbf{7 8}$ \\
Dimokratia & $\mathbf{7}$ \\
Total number & $\mathbf{3 2 5}$
\end{tabular}

Accordingly, we collected all articles published by their online editions and we calculated separately the number of news reports and opinions. By focusing on the balance between these two categories, we explored the newspapers' emphasis (news vs. views) with regard to both the Skripal case and Russia. We also measured the number of reports signed by newspapers' journalists compared to the number of reports coming from the news agencies. This is another indicator of the particular interest of the newspapers not only to inform on the story and the case but also to develop their particular approach compared to the more neutral one as presented by the news agencies (Palmer, 2003).

We codified the headlines of all the articles on the basis of their "Point of view" value. The "Point of view" refers to whether the headline presents the case in relation to an action or reaction of Russia or a country of the West. The cases where none of the above options could be applied were attributed neutral values. Examples of the coding scheme are presented in Table 2. Coding was modeled according to the "descriptive coding method" which aims at providing the summary of the basic topic and the substance of the message and not merely an abbreviation of the content (Wolcott, 1994; Saldana, 2013).

Table 2. Examples of codification of the headlines according to the point of view

\begin{tabular}{|c|c|}
\hline Headlines & "Point of view" value \\
\hline $\begin{array}{l}\text { "Moscow is on the attack for the Skripal case" } \\
\text { (Avgi Newsroom, 2018) }\end{array}$ & Russia's point of view \\
\hline $\begin{array}{l}\text { "Moscow denies that it has developed chemical } \\
\text { weapons" }\end{array}$ & Russia's point of view \\
\hline \multicolumn{2}{|l|}{ (To Vima Team, 2018) } \\
\hline "New US sanctions against Russia" & West's point of view \\
\hline \multicolumn{2}{|l|}{ (Avgi Newsroom, 2018) } \\
\hline "The British accuse Putin for the spy thriller" & West's point of view \\
\hline \multicolumn{2}{|l|}{ (Kapetanopoulou, 2018c) } \\
\hline "The Cold War between the West and Russia" & Neutral \\
\hline \multicolumn{2}{|l|}{ (Kathimerini Newsroom, 2018) } \\
\hline $\begin{array}{l}\text { "A spy mystery is unfolding in Salisbury" } \\
\text { (Kathimerini Newsroom, 2018) }\end{array}$ & Neutral \\
\hline
\end{tabular}

In the following stage, we codify the references to Russia according to their tone; we distinguished a positive, a
negative and a neutral one, on the basis of the "media valence" framework. Affective and evaluative elements such as 
the positive, negative and neutral tone is one of key elements of media valence (Lee \& Carroll, 2011), while "media not only affect the salience of objects (i.e. issues, candidates) in the news, but the salience of object attributes (properties and qualities)" (Kiousis, 2004: p.76). Thus, taking "Russia" as the main object of interest, our codification regarded all content that included evaluative attributes related to Russia. In this way, our coding is not guided by lexicometry (i.e. how many times Russia or other countries are referred to in the headlines) but by the detection of patterns (topic) in the content. This approach adds to the validity of the codification as it is not sensitive to the authors' writing style but to the codifiers systematic interpretation. In particular, positive tone as a favorable disposition towards the object itself (Russia) or one of its attributes (i.e. politicians, society, economy, politics, history, international relations), negative tone as an unfavorable disposition towards the object and its attributes and neutral as the absence of both favorable and unfavorable.

This codification regarded both opinions and signed news reports. In total, sixty-seven articles $(\mathrm{N}=67)$ and one hundred and ninety separate references $(\mathrm{N}=190)$ were coded. This is the total amount of references to Russia in this particular group of articles (signed news reports and opinions). Table 3 contains examples of this codification.

Table 3. Examples of codification of the references to Russia according to their tone

\begin{tabular}{ll}
\hline References & Tone of the reference \\
\hline "Putin fulfills the profile of the ideal leader: he is unflinching, decisive, humorous & Favorable to Russia \\
and tough. The Right in the West, and especially in Orthodox Greece, cannot but & \\
have sympathies for Putin" (Doumas, 2018) &
\end{tabular}

"In a pressing situation like this, the people stand by their leader. The Skripal case gave Putin the opportunity to appear decisive and powerful" (To Vima Team, 2018)

Favorable to Russia

"It doesn't matter if the Russian autocratic leader imprisons his opponents. It

Unfavorable to Russia doesn't matter if he sends agents to Britain in order to assassinate his opponents. In Greece, there are people who think he merits an award for his policies" (Mandravelis, 2018)

"Putin has managed to convince the Russian public opinion that in a difficult situation he is the only one who can guarantee security, in spite of the authoritarianism and the ruthless nature of its power, that even his voters criticize him for" (Gerantoni, 2018)

"The mutual accusations between Britain and Russia are steadily increasing" Neutral (Kapetanopoulou, 2018b)

Unfavorable to Russia

"The Cold War-like confrontation between London and Moscow is taking extreme Neutral forms" (Kapetanopoulou, 2018a)

The reliability of our coding was attained as follows. Both authors served as the main coders for both types of codification, namely the headlines' point of view and the tone. In a preparatory stage, we selected a subsample divided into two groups: forty articles for the coding of headlines and forty articles for the coding of the tone. The subsample for the tone was composed of both news reports and opinions. This pre-coding stage helped to establish the rate of intercoder reliability. Using Fleiss' kappa measure we produced a rather high rate of agreement for the codification of the headlines $(0.78)$ and a lower one, still significant, (0.71) for the tone. Instead of duplicating the codification for the entire sample, we proceeded by assigning equal parts to the coders. Our aim was to make sure that they both codified every newspaper both in terms of the headlines and the tone.

Lastly, we should clarify a discrepancy when it comes to the number of articles coded from the standpoint of the headlines $(\mathrm{N}=325)$ and the tone $(\mathrm{N}=67)$. This is due to our choice to prioritize original content (articles signed by journalists or other personalities such as experts) and not syndicated content (news reports based on the information provided by the news agencies). We are very well aware that even in the case of the syndicated content, a newspaper may modify elements of its content (particularly the headline). However, our choice served the purpose of studying the tone as closely as possible to a newspaper's distinctive approach. 


\section{Results and Discussion}

Our first hypothesis helps us obtain a more systematic understanding on the typology of Russia's coverage while the second one categorizes different dispositions according to the different sub- cultures exemplified by the outlets of our sample.

\section{H1. The discomfort towards the Skripal case}

The dominant pattern of the coverage of the Greek newspapers includes numerous news reports and very few opinions. This is attributed to a generalized effect of awkwardness. This consisted of the choice not to analyze the Skripal case, arguably due to the fact that hard or soft Russophilia would be difficult to adjust to the media agenda setting. In essence, this implies a certain predisposition on their audience's reception. In our view, this is read as a choice not to offer much, almost none, analysis on Russia. In effect, faced with the urgency to cover the Skripal case, the Greek newspapers viewed the case within the framework of covering Russia for the Greek public (mediatization); each newspaper inevitably adjusted this coverage to its particular attitudes and dispositions towards Russia (domestication). Our empirical data indicate that when it comes to the analysis on the Skripal case, it appears to be a rather dominant pattern across all newspapers and orientations.

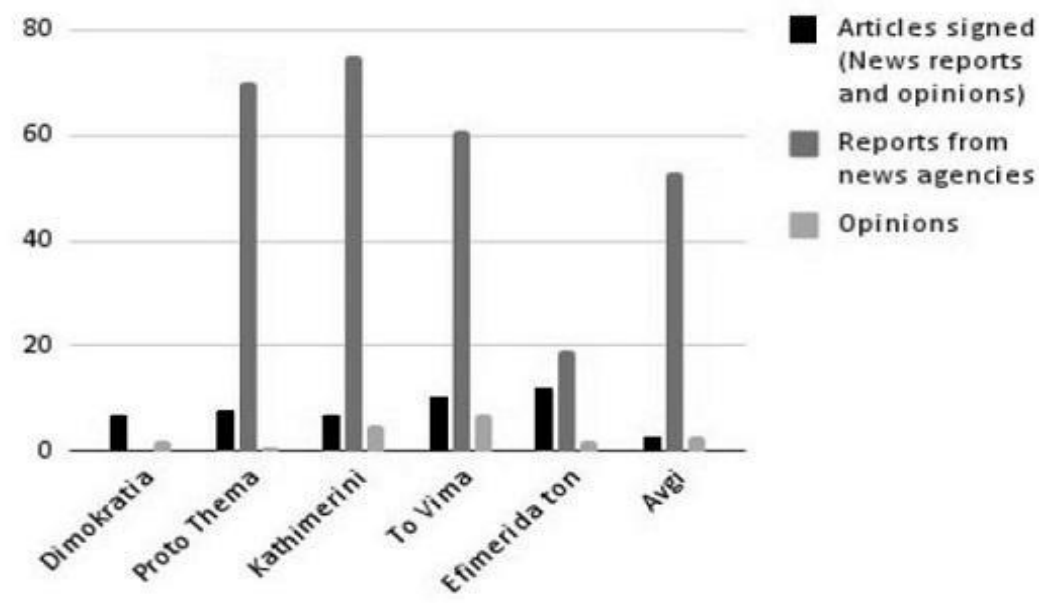

Figure 1. Number of reports and opinions published by the newspapers of our sample on the Skripal case in the period of March 2018

Data in figure 1 indicate an overwhelming preference to cover the Skripal case via news reports. Op-eds are very few $(\mathrm{N}=20$ or $6 \%$ of the total number of articles) in all cases. Even if we include the number of signed news reports ( $N=47$ or $14 \%$ of the total number of published articles), the outlook is not significantly different. These figures lead us to the assumption that albeit their keen interest for the case or Russia, the Greek newspapers chose to cover the story through news reports from major news agencies.

The comparison of the news/views balance among different media outlets works as a proxy informing on their interest for a topic that they are very well aware of. Studies on newspaper genres and their impact on the way the media frame reality do not measure the ratio between op-eds and news reports. Nonetheless, it's news reports that dominate the coverage and not op-eds. In our case, we interpret the absence of op-eds as a limited will to mediate events in relation to the newspapers' adopted approaches.

The striking absence of opinions as well as news reports on the Greek policies and reactions also validates this hypothesis. As it was already noted, the most relevant article was a news report by Bloomberg ("May Served Secrets Over Dinner to Win EU Allies for Russia Fight", March 23, 2018), republished by Kathimerini. The fact that Greece was among the EU countries that did not expel any Russian diplomats or that it opposed harsh measures was not picked up by the newspapers. There was only one commentary in Kathimerini (Peloni, 2018). It merely referred to the government's position which favored a resolution based on discussions and not the escalation of tension with Russia 


\section{H2: Differentiations in the image of Russia according to different sub-cultures}

$\mathrm{H} 2$ regards the identification of the different depictions of Russia on the basis of distinct subcultures expressed by the newspapers. As the coverage in the newspapers is dominated by news reports, rather than views, a sub-question emerges implying whether the newspapers adopt the same approach and interpretative patterns towards Russia.

The first set of data addresses this question by considering the codification of the newspapers' headlines according to the different points of view (three values: i. Russia's point of view, ii. Neutral and iii. West's point of view).

Table 4. Distribution of the newspapers' headlines according to their point of view

\begin{tabular}{llll}
\hline Newspapers & $\begin{array}{l}\text { Russia's point of } \\
\text { view }\end{array}$ & Neutral & $\begin{array}{l}\text { West's point of } \\
\text { view }\end{array}$ \\
\hline Avgi & $\mathbf{3 5 \%}$ & $17 \%$ & $\mathbf{4 8 \%}$ \\
Efimerida ton Syntakton & $17 \%$ & $\mathbf{3 7 \%}$ & $\mathbf{4 6 \%}$ \\
To Vima & $29 \%$ & $23 \%$ & $\mathbf{4 8 \%}$ \\
Kathimerini & $30 \%$ & $29 \%$ & $\mathbf{4 1 \%}$ \\
Proto Thema & $\mathbf{3 7 \%}$ & $19 \%$ & $\mathbf{4 4 \%}$ \\
Dimokratia & $29 \%$ & $\mathbf{7 1 \%}$ & - \\
\hline
\end{tabular}

Table 4 data indicate a major recurring pattern. With the exception of the right-wing Dimokratia, there is a clear emphasis on the West's point of view in all other newspapers. This is highly significant because it suggests that most newspapers- independently of their views on Russia or the Skripal case- prioritized the Western countries' actions or standpoints. Nevertheless, it does seem that the most important scores for Russia's point of view and the neutral point of view are found in the left and right orientations and not the centre. However, these are not as consistent as the emphasis on the West's point of view. The results of the codification of references to Russia found in news reports and opinions according to their tone indicate the domestication process at work (Table 5). There is an important degree of similarity with west-side imbalance.

Table 5. Distribution of the references to Russia according to their tone

\begin{tabular}{llll}
\hline Newspapers & Positive & Neutral & Negative \\
\hline Avgi & $10 \%$ & $\mathbf{7 0 \%}$ & $20 \%$ \\
Efimerida ton Syntakton & $28 \%$ & $\mathbf{4 7 \%}$ & $25 \%$ \\
To Vima & $20 \%$ & $18 \%$ & $\mathbf{6 2 \%}$ \\
Kathimerini & $14 \%$ & $43 \%$ & $\mathbf{4 3 \%}$ \\
Proto Thema & $\mathbf{3 0 \%}$ & $32 \%$ & $28 \%$ \\
Dimokratia & $\mathbf{3 4 \%}$ & $39 \%$ & $27 \%$
\end{tabular}

Furthermore, there are clearly distinguishable patterns across specific groups. The most positive dispositions towards Russia are found in newspapers with right orientation (Dimokratia and Proto Thema). The most neutral ones are found in newspapers with a left orientation (Avgi and Efimerida ton Syntakton) and the most negative ones in the newspapers with a strong connection to the centre (Kathimerini and To Vima). These data are related to deeper elements (attitudes, perceptions, knowledge) pertaining to Russia.

Schematically, we could identify two core dimensions: firstly, even in cases where the informative articles dominate or where the opinions are sporadic, the newspapers can still adjust a story to their distinct patterns of presenting an actor or even a country. The emphasis on news rather than views does not necessarily imply a more homogenous coverage of the newspapers. Secondly, there are plenty of positive inclinations towards Russia; this is one out of four of the total 
number of references coded (the corresponding percentages for the other tones are $42 \%$ for the neutral and $35 \%$ for the negative). Nonetheless, it is important to note that in the context of a topic unfavorable for Russia, there is a significant rate of Russophile dispositions.

In the case of positive references, a dominant theme regards President Putin as a leader and the positive impact of his policies for Russia and its standing in world affairs (i.e. strong leadership, powerful country, reconstruction under Putin, approval of Putin's policies by Russians). Such references can be found across all newspapers and mostly in right-wing Dimokratia. Similarly, the only positive depictions of Russia in relation to the specific event of the Skripal case -the idea that most probably there is not enough evidence incriminating Russia- is found in Dimokratia and also Efimerida ton Syntakton. In the case of Dimokratia the positive perceptions on Russia seem to have not only a political but a cultural overtone as well, while most of the positive references relate to President Putin.

"Essentially, no substantive evidence has been put forth that incriminates the "Russian bear", something which illustrates once more the meaningless arrogance of the Western elite."

(Doumas, 2018)

"Is sympathy for Russia and especially for Vladimir Putin a right-wing disposition, given that Putin has an organic relation to the former soviet regime? (...) The Right in the West- and particularly in Orthodox Greececannot but have sympathies for Putin. Maybe because it realizes that the real confrontation is not between West and East but between the traditional Christian culture and the heavy-handed Islam.”

(Doumas, 2018)

“ (...) Primarily, it has to do with the fact that Putin, who found his way upon the post-soviet wreckage, managed to get Russia out of the fringes and reconstruct its lost prestige (...) Thus the Russian President brought the foreign policy into the centre of the electoral discussions and referred to the sentiment of a revived patriotism."

(Gerantoni, 2018)

Neutral dispositions relate to the idea that the Skripal case signifies the worsening of relations between Russia and the West to a point that can be described as a "New Cold War". This consists of a common formula in all the newspaper studies. It can be argued that these references are the most relevant to the specificities of the Skripal case, as they reflect elements of the interpretation of the newspapers in regard to the implications of the variety of developments.

In a similar vein, the negative ones can be divided into two categories: one that relates to Russia's responsibility for the attack and a second one that refers to more general perceptions and in particular the authoritarian nature of the power exercised by President Putin. Emphatically, while the references to the responsibility of Russia and President Putin are found in all the newspapers, the ones that relate to its power are mostly found in Kathimerini and To Vima. These two newspapers interpreted the Skripal case in the wider framework of the Russian President's policies.

To sum-up, the importance of the different subcultures is salient. As the domestication theory posits, this determines the presentation of foreign news, and particularly of actors or countries. Despite the detection of traits that indicate a rather homogenized coverage we identified distinctive interpretations and dispositions towards Russia. One way to explain these patterns could relate to the newspapers' political orientation.

\section{Conclusions}

Our study provides insights for the identification and the interpretation of Greek media attitudes towards Russia. We assessed a perplexing mode of coverage, encapsulated by the 'more news than views' approach. In fact, as we expected more views and analysis, we addressed the hypothesis of a discomfort in media coverage. This expectation was grounded on the considerable rates of Russophilia in Greek society, as are measured by using the public opinion as proxy. Also, this was a case which spawned an international diplomatic crisis in which Greece was not aligned with its Western allies. The awkward approach of the Greek newspapers was illustrated by a special interest in the case but without an elaborate analysis of its implications including Greek government policies.

We also identified the different subcultures when it comes to presenting Russia, by showing that the newspapers' political orientation is an indicator of distinct dispositions. Thus, it was established that the most positive stances are found in the right, the more neutral in the left and the most negative in the centre. Our analysis validates the detection of precise inclinations. In effect, Russophile dispositions were not the most dominant; to the extent that they were shared by all newspapers they regarded the positive impact of President Putin for his country. The same counts for the negative. One could argue that media with right wing orientation tend to be more positive than the rest. Media with left wing orientation tend to be more neutral and those that relate to the centre more negative.

Overall, the Greek newspapers do present and represent Russia in different ways. Certainly, there are potential 
limitations to the applicability of our remarks. Our study focused on the attitudes on Russia in the context of international affairs. Similar hypotheses should be tested in the context of case studies regarding Russia's domestic situation and the bilateral Greek-Russian relations. This could offer a more comprehensive understanding of the Russophilie dispositions in the media. From our standpoint, we are able to ascertain that the most important element for positive perceptions is President Putin. The same seems to be valid for the negative ones. More case studies will enrich this assessment.

\section{References}

Alasuutari, P., Qadir, A., \& Creutz, K. (2013). The domestication of foreign news: news stories related to the 2011 Egyptian revolution in British, Finnish and Pakistani newspapers. Media, Culture \& Society, 35(6), 692-707. https://doi.org/10.1177/0163443713491299

Anderson, B. (1983). Imagined Communities: Reflections on the Origin and Spread of Nationalism. New York, NY: Knopf Doubleday Publishing Group.

Armakolas, I., \& Siakas, G. (2021). "Why did it take so long?" Exploring Greek public opinion as an obstacle to the settlement of the Macedonia name dispute. Nationalities Papers, 1-20. https://doi.org/10.1017/nps.2021.7

Armakolas, I., \& Triantafyllou, G. (2017). Greece and EU enlargement to the Western Balkans: understanding an ambivalent relationship. Southeast European and Black Sea Studies, 17(4), 611-629. https://doi.org/10.1080/14683857.2017.1407399

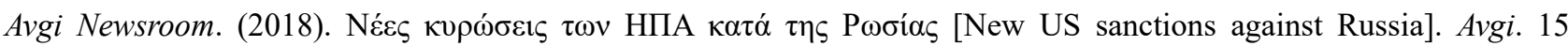
March.

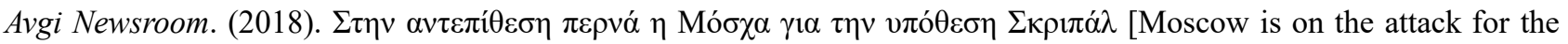
Skripal case]. 31 March.

Baden, C., \& Tenenboim-Weinblatt, K. (2017). Convergent News? A Longitudinal Study of Similarity and Dissimilarity in the Domestic and Global Coverage of the Israeli-Palestinian Conflict. Journal of Communication, 67(1), 1-25. https://doi.org/10.1111/jcom.12272

Baum, M., \& Potter, P. (2008). The Relationships Between Mass Media, Public Opinion, and Foreign Policy: Toward a Theoretical Synthesis. Annual Review of Political Science, 11(1), 39-65. https://doi.org/10.1146/annurev.polisci.11.060406.214132

Beckers, K., Masini, A., Sevenans, J., van der Burg, M., De Smedt, J., Van den Bulck, H., \& Walgrave, S. (2019). Are newspapers' news stories becoming more alike? Media content diversity in Belgium, 1983-2013. Journalism, 20(12), 1665-1683. https://doi.org/10.1177/1464884917706860

Bennett, W., \& Entman, M. (2001). Mediated politics. Cambridge, UK: Cambridge University Press.

Boukala, S., \& Dimitrakopoulou, D. (2017). Absurdity and the "Blame Game" Within the Schengen Area: Analyzing Greek (Social) Media Discourses on the Refugee Crisis. Journal of Immigrant \& Refugee Studies, 16(1-2), 179-197. https://doi.org/10.1080/15562948.2017.1303560

Boyd-Barrett, O. (1997). Global news wholesalers as agents of globalization. In A. Sreberny, Media in global context: A reader (pp. 131-144). London, UK: Arnold.

Boyd-Barrett, O., \& Mirrlees, T. (2020). Media imperialism: Continuity and Change. Lanham, MD: Rowmand \& Littlefield Publishers.

Boyd-Barrett, O., \& Rantanen, T. (1998). The Globalization of News. London, UK: Sage.

Charaudeau, P., \& Maingueneau, D. (2002). Dictionnaire d'analyse du discours. Paris, France: Éditions du Seuil.

Clausen, L. (2004). Localizing the Global: 'Domestication' Processes in International News Production. Media, Culture \& Society, 26(1), 25-44. https://doi.org/10.1177/0163443704038203

Deutsche Welle. (2022). Russia denies knowledge of Sergei Skripal poisoning in Salisbury | DW | 06.03.2018. DW.COM. Retrieved 19 January 2022, from

https://www.dw.com/en/russia-denies-knowledge-of-sergei-skripal-poisoning-in-salisbury/a-42844139

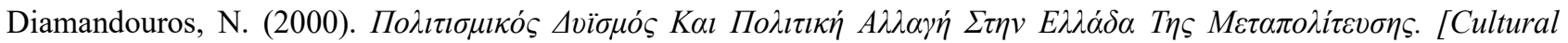
Dualism and Political Change in Postauthoritarian Greece]. Athens, Greece: Ekdoseis Alexandreia.

DiaNeosis. (2016-2020). “What Greeks believe”, results of yearly opinion polls. Dianeosis. Retrieved 15 July 2021, from https://www.dianeosis.org/en/ 


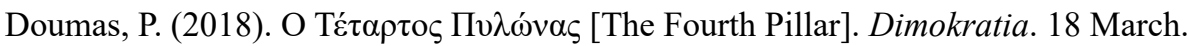

Efthymiopoulos, M. (2016). Immunity from Western Policy Orientation: Revising the Relations between Greece and Russia. Comparative Politics (Russia), 7(1(22), 83-98. https://doi.org/10.18611/2221-3279-2016-7-1(22)-83-98

Entman, R. (2003). Cascading Activation: Contesting the White House's Frame After 9/11. Political Communication, 20(4), 415-432. https://doi.org/10.1080/10584600390244176

Erlanger, S. (2018). How an Outraged Europe Agreed to a hard line on Putin. The New York Times. 26 March.

Galtung, J., \& Ruge, M. (1965). The Structure of Foreign News. Journal Of Peace Research, 2(1), 64-90. https://doi.org/10.1177/002234336500200104

Galtung, J., \& Vincent, R. (1992). Global Glasnost: Toward a New World Information and Communication Order?. Cresskill, NJ: Hampton Press.

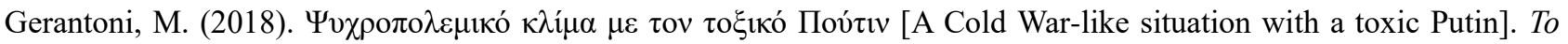
Vima. 18 March.

Gurevitch, M., Levy, M., \& Roeh, I. (1991). The global newsroom: convergences and diversities in the globalization of television news. In P. Dahlgren \& C. Sparks (Eds.), Communications and Citizenship: Journalism and the Public Sphere in the New Media Age. London, UK: Routledge.

Handley, R., \& Ismail, A. (2010). Territory under siege: 'their' news, 'our' news and 'ours both' news of the 2008 Gaza crisis. Media, War \& Conflict, 3(3), 279-297. https://doi.org/10.1177/1750635210364690

Hänni, A., \& Grossmann, M. (2020). Death to traitors? The pursuit of intelligence defectors from the Soviet Union to the Putin era. Intelligence And National Security, 35(3), 403-423. https://doi.org/10.1080/02684527.2020.1728046

Hille, K., \& Bond, D. (2018). Russia denies role in nerve agent attack on former spy Skripal. Financial Times. 9 March.

Hjarvard, S. (2008). The Mediatization of Society: A theory of the Media as Agents of Social and Cultural Change. Nordicom Review, 29(2), 102-131. https://doi.org/10.1515/nor-2017-0181

Hjarvard, S. (2013). The mediatization of culture and society. London, UK: Routledge. https://doi.org/10.4324/9780203155363

Huang, C. (2020). International opinion of Russia and Putin remains negative in 2020. Pew Research Center. Retrieved 19 January 2022, from https://www.pewresearch.org/fact-tank/2020/12/16/views-of-russia-and-putin-remain-negative-across-14-nations/

Huang, C., \& Cha, J. (2020). Russia and Putin receive low ratings globally. Pew Research Center. Retrieved 19 January 2022, from https://www.pewresearch.org/fact-tank/2020/02/07/russia-and-putin-receive-low-ratings-globally/.

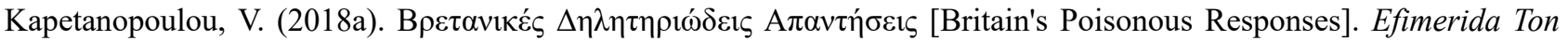
Syntakton. 19 March.

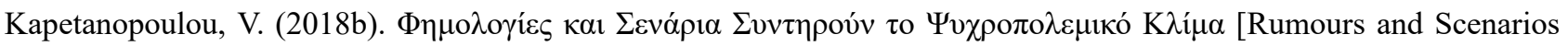
sustain the Cold War Situation]. Efimerida Ton Syntakton. 20 March.

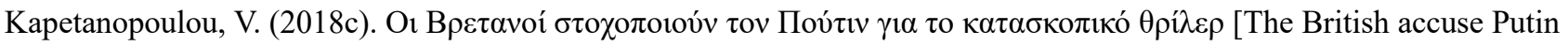
for the spy thriller]. Efimerida Ton Syntakton. 17 March.

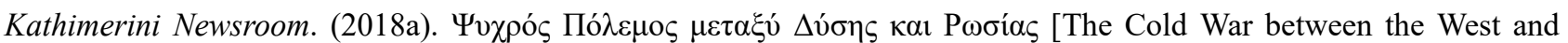
Russia]. Kathimerini. 16 March.

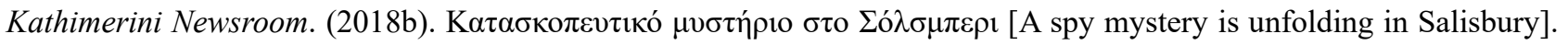
Kathimerini. 7 March.

Kiousis, S. (2004). Explicating Media Salience: A Factor Analysis of New York Times Issue Coverage During the 2000 U.S. Presidential Election. Journal of Communication, 54(1), 71-87. https://doi.org/10.1111/j.1460-2466.2004.tb02614.x

Kruger, K., Lukowiak, A., Sonntag, J., Warzecha, S., \& Stede, M. (2017). Classifying news versus opinions in newspapers: Linguistic features for domain independence. Natural Language Engineering, 23(5), 687-707. https://doi.org/10.1017/s1351324917000043

Lee, S., \& Carroll, C. (2011). The Emergence, Variation, and Evolution of Corporate Social Responsibility in the Public Sphere, 1980-2004: The Exposure of Firms to Public Debate. Journal Of Business Ethics, 104(1), 115-131. https://doi.org/10.1007/s10551-011-0893-y

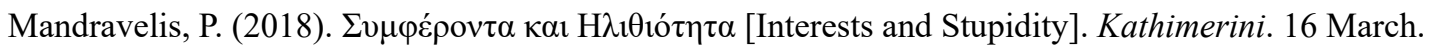




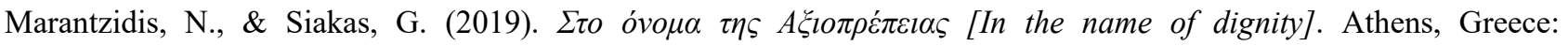
Papadopoulos.

Mazzoleni, G. (2008). Mediatization of Politics. In W. Donsbach (Ed.). The International Encyclopedia of Communication (pp. 3047-3051). Malden, MA: Blackwell Pub. https://doi.org/10.1002/9781405186407.wbiecm062

Mazzoleni, G., \& Schulz, W. (1999). "Mediatization" of Politics: A Challenge for Democracy? Political Communication, 16(3), 247-261. https://doi.org/10.1080/105846099198613

McLuhan, M. (1964). Understanding media. New York, NY: McGraw-Hill..

Mouffe, C. (2002). Which Public Sphere for a Democratic Society?. Theoria, 49(99). https://doi.org/10.3167/004058102782485448

Nikisianis, N., Siomos, T., Stavrakakis, T., Markou, Y., \& Dimitroulia, T. (2018). Populism Versus Anti-populism in the Greek Press: Post - Structuralist Discourse Theory Meets Corpus Linguistics. In T. Martila, Discourse, Culture and Organization: Inquiries into Relational Structures of Power. London, UK: Palgrave Macmillan. https://doi.org/10.1007/978-3-319-94123-3_12

Ntampoudi, I. (2014a). Reflections on the (Greek) underdog culture: A rebellious and radical political identity?. In 64th Political Studies Association, Annual International Conference, "Rebels and Radicals". Manchester; Political Studies Association. 14-16 April.

Ntampoudi, I. (2014b). The Greek 'underdog' political culture: An Anti-European political identity?. In The Third Euroacademia International Conference: 'The European Union and the Politicization of Europe'. Lisbon. 26-27 September.

Oxford Analytica. (2020). Russia will continue cautious covert action in Balkans. Oxford Analytica Daily Brief. Retrieved 19 January 2022, from https://dailybrief.oxan.com/Analysis/ES250731/Russia-will-continue-cautious-covert-action-in-Balkans

Palmer, M. (2003). Quels mots pour le dire? Correspondants de guerre, journalistes et historiens face aux conflits yougoslaves . Paris, France: L'Harmattan.

Papadogiannis, N. (2019). Brexit from Greek Vantage Points: Changing Histories in the United Kingdom and Greece. Contemporary European History, 28(1), 27-30. https://doi.org/10.1017/s0960777318000735

Parks, P., \& Takahashi, B. (2016). From Apes to Whistleblowers. Science Communication, 38(3), 275-302. https://doi.org/10.1177/1075547016642240

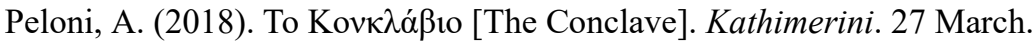

Petsinis, V. (2014). Eurasianism and the Far Right in Central and Southeast Europe. Central Eastern European Review, 8(1), 1-10. https://doi.org/10.2478/caeer-2014-0005

Petsinis, V. (2016). Russophilia as a component of national populism in Greece. Критика И Хуманизъмпо, 46, 281-298.

Rasmussen, T. (2016). The Internet Soapbox, Perspectives on a Changing Public Sphere. Oslo, Norway: Universitetsforlaget.

Ross, T., Dendrinou, V., \& Krukowska, E. (2018). May Served Secrets Over Dinner to Win EU Allies Support for Russia Fight. Bloomberg. 23 March. Retrieved 19 January 2022, from https://www.bloomberg.com/news/articles/2018-03-23/may-served-secrets-over-dinner-to-win-eu-allies-for-russiafight.

Saldaña, J. (2013). The coding manual for qualitative researchers. London, UK: Sage.

Shehata, S., \& Stromback, J. (2014). Mediation of Political Realities: Media as Crucial Sources of Information. In F. Esser \& j. Stromback, Mediatization of Politics, Understanding the transformation of Western Democracies. London, UK: Palgrave Macmillan.

Siakas, G., \& Paschalidis, P. (2021). Variants of the 'underdog culture' in Greek public opinion: soft and hard-core Russophilia. Southeast European and Black Sea Studies, 21(1), 31-52. https://doi.org/10.1080/14683857.2021.1873578

Sommer, B., \& Maycroft, J. (2008). Influencing Public Policy: An Analysis of Published Op-Eds by Academics. Politics \& Policy, 36(4), 586-613. https://doi.org/10.1111/j.1747-1346.2008.00122.x 
Sterling, C. (2009). Encyclopedia of journalism. London, UK: Sage. https://doi.org/10.4135/9781412972048

Strömbäck, J. (2008). Four Phases of Mediatization: An Analysis of the Mediatization of Politics. The International Journal of Press/Politics, 13(3), 228-246. https://doi.org/10.1177/1940161208319097

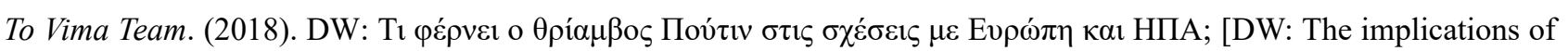
Putin's triumph for the relations with Europe and the USA]. To Vima. 19 March.

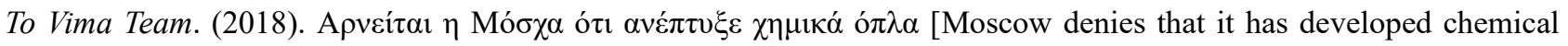
weapons]. To Vima. 15 March.

Tsebelis, G. (2016). Lessons from the Greek crisis. Journal of European Public Policy, 23(1), 25-41. https://doi.org/10.1080/13501763.2015.1087215

Tzogopoulos, G. (2020). Greek-Russian relations: a potential to mend strained ties. Athens, Greece: ELIAMEP.

van der Meer, T., Kroon, A., Verhoeven, P., \& Jonkman, J. (2018). Mediatization and the Disproportionate Attention to Negative News. Journalism Studies, 20(6), 783-803. https://doi.org/10.1080/1461670x.2018.1423632

Verluise, P. (2018). The Skripal Case: A Revealing Sign of the New Post-Cold War Geopolitical Reshuffle?. Diploweb.com. Retrieved 19 January 2022, from

https://www.diploweb.com/The-Skripal-Case-A-Revealing-Sign-of-the-New-Post-Cold-War-Geopolitical-Reshuffl e.html

Wolcott, H. (1994). Transforming qualitative data. Londo, UK: Sage.

Zahariadis, N. (2017). Bargaining power and negotiation strategy: examining the Greek bailouts, 2010-2015. Journal of European Public Policy, 24(5), 675-694. https://doi.org/10.1080/13501763.2016.1154977

\section{Copyrights}

Copyright for this article is retained by the author(s), with first publication rights granted to the journal.

This is an open-access article distributed under the terms and conditions of the Creative Commons Attribution license which permits unrestricted use, distribution, and reproduction in any medium, provided the original work is properly cited. 